\title{
Peran Badan Pengurus Jemaat Dalam Meningkatkan Pertumbuhan Kerohanian Pemuda Gereja Kristen Sulawesi Barat Efata Di Desa Salutiwo Mamuju
}

\author{
Nofandi
}

\begin{abstract}
Abstrak
Adapun tujuan penulisan skripsi ini, adalah: Untuk menemukan peran badan pengurus jemaat Gereja Kristen Sulawesi Barat terhadap kualitas pertumbuhan kerohanian pemuda jemaat Efata Desa Salutiwo di Mamuju. Berdasarkan hasil penelitian maka penulis menyimpukan bahwa: Pertama, bertumbuhnya iman seseorang dalam jemaat khususnya bagi pemuda ditentukan oleh peranan seorang pemimpin dalam gereja khususnya peranan badan pengurus jemaat kepada pemuda. Kedua, pelayanan yang dilakukan oleh badan pengurus jemaat kepada pemuda, merupakan hal yang terpenting dari yang terpenting, maksudnya ialah karena pemuda dalam gereja merupakan ujung tombak yang akan mengembangkan dan meneruskan gereja dimasa yang akan datang. Ketiga, pemuda harus dilayani dengan baik, artinya bahwa ketika pemuda tidak dilayani dengan baik maka pelayanan yang akan di berikan kepada mereka tidak akan membawa dampak yang positif bagi dirinya dan kepada orang lain yang ada disekitarnya. Keempat, sebagai pelayan Tuhan khususnya badan pengurus jemaat harus bisa memberikan teladan rohani yang baik kepada pemuda, agar pemuda dapat mengikuti dan menjadikan BPJ sebagai panutan yang baik kepada dirinya. Kelima, pemuda harus diperlengkapi sebagai generasi muda dalam gereja untuk mengembangkan potensi yang mereka miliki tujuannya untuk ikut terlibat dalam pelayanan dalam gereja maupun diluar gereja. Keenam, sebagai pelayan Tuhan khususnya badan pengurus jemaat harus bisa melibatkan dan memanfaatkan pemuda dalam pelayanan, agar pemuda dapat memberikan potensinya kepada gereja terutama kepada Tuhan. Ketujuh, badan pengurus jemaat dapat mempersiapkan pemuda sebagai pemimpin dimasa yang akan datang untuk meneruskan dan mengembangkan pelayanan dalam gereja maupun diluar gereja.
\end{abstract}

Kata-kata Kunci: Peran, Pengurus, Pertumbuhan, Kerohanian, Pemuda, GKSB, Salutiwo, Mamuju. 


\section{Pendahuluan}

\section{Latar Belakang Masalah}

Masa muda adalah masa yang paling berpotensi dalam tahap kehidupan manusia gereja harus menjadikan pemuda sebagai tiang yang utama dalam gereja. Perkembangan zaman yang begitu pesat sangat mempengaruhi kehidupan manusia secara khusus untuk kaum muda Kristen. Oleh sebab itu, badan pengurus jemaat haruslah menjalankan perannya sebagai pelayan Tuhan, untuk meningkatkan pertumbuhan kerohanian pemuda. Pelayanan kepada pemuda untuk meningkatkan pertumbuhan kerohanian pemuda sangatlah penting dan menentukan masa depan gereja yang dilakukan oleh badan pengurus jemaat.

Pelayanan yang dilakukan oleh badan pengurus jemaat kepada pemuda Kristen dalam gereja untuk membimbing dan menolong setiap kaum muda dalam gereja untuk pembentukan kepribadiannya sesuai dengan standar Firman Tuhan. Oleh sebab itu, setiap pemuda di gereja membutuhkan pelayan Tuhan yang benarbenar ingin melayani pemuda, khususnya badan pengurus jemaat telah ditunjuk oleh jemaat untuk melayani dan menangani pemuda dalam gereja. Dalam meningkatkan pertumbuhan kerohanian pemuda untuk pengenalan akan Yesus Kristus, badan pengurus jemaat harus mempedulikan dan berperan aktif untuk pemuda agar mereka tidak terbawa oleh arus dunia ini. Selain dari itu, badan pengurus jemaat harus menjalankan perannya sebagai pelayan Tuhan dalam meningkatkan pertumbuhan kerohanian pemuda. Pelayanan kepada pemuda untuk meningkatkan kerohanian mereka yang dilakukan oleh badan pengurus jemaat kepada pemuda sangatlah penting untuk dilakukan karena pemuda merupakan bagian yang terpenting di dalam gereja, dan masa muda adalah masa transisi di mana kaum muda sangat membutuhkan bimbingan. Charles. M. Shelton mengatakan,

Masa muda adalah proses peralihan masa kanak-kanak menuju masa dewasa, suatu masa yang menentukan perkembangan dan perubahan, masa goncang dan penuh pemberontakan. Tidak jarang kita temui banyak kaum muda kehilangan pegangan dalam usaha menentukan dirinya. Dalam masa ini kaum muda memang membutuhkan pendampingan kaum dewasa, yang bisa memahami dan melindungi mereka tumbuh dewasa. ${ }^{1}$

Dengan keadaan seperti itu kaum muda membutuhkan pelayan Tuhan yang benar-benar ingin meningkatkan kerohanian pemuda untuk pembentukan kerohanian mereka, karena generasi muda merupakan pemegang kendali arah pelayanan ke depan. Ketika generasi muda dilayani dengan baik dan kerohanian mereka mulai bertumbuh dengan sebaik mungkin, maka gereja akan bisa maju dan berkembang dan membawa perubahan bagi jemaat yang lain. Ketika badan

\footnotetext{
${ }^{1}$ Charles M. Shelton, Moralitas Kaum Muda (Yogyakarta: Kanisius, 1990), 5.
} 
pengurus jemaat melalaikan pelayanan kepada kaum muda, maka sudah dipastikan bahwa keadaan pelayanan gereja akan mengalami kemunduran yang sangat mempengaruhi rohani jemaat khususnya bagi pemuda gereja. Dengan demikian, bahwa setiap pelayan Tuhan dalam gereja harus memperhatikan dan mempedulikan pelayanan kepada pemuda, tidak dipungkiri lagi sesuai dengan fakta dan berdasarkan kesaksian dari pemuda di gereja setempat bahwa badan pengurus jemaat kurang menjalankan perannya sebagai pelayan Tuhan, kurang memberi perhatian terhadap kaum muda sehingga kerohanian mereka tidak mengalami pertumbuhan dan mengalami kemunduran. Meskipun ada pelayanan yang dilakukan kepada kaum muda, tetapi tidak ada tanda-tanda pertumbuhan kerohanian bagi kaum muda di Gereja Kristen Sulawesi Barat di Jemaat Efata. Ini menujukkan bahwa kurangnya peran yang dijalankan oleh badan pengurus jemaat. Ketika badan pengurus jemaat kurang menjalankan perannya sebagai pelayan Tuhan bagi pemuda, maka kerohanian mereka akan menurun dan tidak mengalami pertumbuhan, ini terlihat dari perilaku dan pergaulan pemuda yang kurang baik sebagai pemuda Kristen misalnya, terlibat dalam rokok, minuman yang beralkohol dan jarang mengikuti persekutuan, baik di gereja maupun di luar gereja. Menurut Obet (samaran ):

Badan Pengurus Jemaat kurang memperhatikan pemuda dalam artian bahwa kurang melayani pemuda dengan baik, Badan Pengurus Jemaat tidak menjalankan perannya sebagai pelayan Tuhan sehingga pemuda terlibat dengan yang kurang baik dan tidak berkenan di mata Tuhan, seperti minumminuman keras, merokok, dll. Badan Pengurus Jemaat tidak mempunyai kepedulian kepada pemuda, ketika Badan Pengurus Jemaat diberi tanggung jawab pelayanan untuk menyampaikan firman Tuhan di ibadah pemuda, Badan Pengurus Jemaat mengatakan sibuk dan akhirnya tidak datang melayani, kadang-kadang juga diserahkan kepada orang lain. ${ }^{2}$

Sebagai pemuda-pemudi Kristen, mereka sedang belajar untuk menjadi pemimpin dan melayani Kristus melalui pertemuan pemuda-pemudi, mereka perlu memahami bahwa orang Kristen dipanggil untuk suatu hidup pelayanan. ${ }^{2}$ Pemuda Kristen haruslah terlibat dalam pelayanan untuk kemuliaan Yesus Kristus, mereka perlu memahami bahwa betapa pentingnya terlibat dalam pelayanan pekerjaan Tuhan. Oleh sebab itu, pemuda sangat membutuhkan mentor untuk melakukan semuanya itu, tetapi hal tersebut tidak bisa tercapai dan tidak bisa terwujud karena peran badan pengurus jemaat kurang dijalankan sebagai pelayan jemaat Tuhan. "Pelayanan kepada kaum muda itu sendiri, bekerja untuk membantu para pemuda untuk mengatasi permasalahan-permasalahan yang mereka hadapi dalam masa

${ }^{2}$ Program Persekutuan Pemuda-pemudi (Bandung: Yayasan Kalam Hidup, 1970), 3. 
remaja, agar mereka dapat berdiri teguh di dalam kedewasaan rohani sesuai dengan usia mereka."3

Pelayanan kepada kaum muda adalah kehormatan bagi setiap pelayan Tuhan. Sebagai badan pengurus jemaat, mereka telah menjadi pemimpin dalam sebuah organisasi gereja secara khusus dalam Gereja Kristen Sulawesi Barat Jemaat Efata. Badan pengurus jemaat harus menjalankan perannya sebagai pelayan Tuhan dan berperan secara aktif bukan secara pasif kepada pemuda untuk melayani pemuda agar kerohaniaan mereka semakin hari semakin bertumbuh dan membawa dampak bagi dirinya. Peran badan pengurus jemaat hanyalah sebagai rutinitas dan tradisi dalam sebuah gereja, tidak menjalankan perannya sebagai pelayan Tuhan dalam sebuah organisasi gereja atau pemimpin dalam mengarahkan jemaat secara khusus untuk kaum muda. Oleh sebab itu, badan pengurus jemaat belum bertindak sebagai pelayan Tuhan dan sebagai pemimpin dalam gereja tersebut, dan masih kurang menjalankan perannya bagi jemaat Tuhan.

\section{Pokok Masalah}

Berdasarkan latar belakang masalah di atas, maka rumusan masalah yang dapat disusun, yakni: bagaimana peran badan pengurus jemaat dalam meningkatkan pertumbuhan kerohanian pemuda Gereja Kristen Sulawesi Barat Efata Desa Salutiwo di Mamuju?

\section{Tujuan Penelitian}

Adapun tujuan penulisan skripsi ini adalah untuk menemukan peran badan pengurus jemaat Gereja Kristen Sulawesi Barat terhadap kualitas pertumbuhan kerohanian pemuda jemaat Efata Desa Salutiwo di Mamuju.

\section{Manfaat Penelitian}

Adapun manfaat dari penulisan skripsi ini adalah:

Pertama, Dapat dijadikan sebagai acuan bagi gereja, khususnya dalam melaksanakan tugas dan peran sebagai badan pengurus jemaat Gereja Kristen Sulawesi Barat Efata Salutiwo.

Kedua, menjadi pedoman bagi gereja, secara khusus Gereja Kristen Sulawesi Barat Efata dalam meningkatkan pertumbuhan kerohanian pemuda.

Ketiga, sebagai sumbangan kepada gereja khususnya untuk badan pengurus jemaat Gereja Kristen Sulawesi Barat Efata Salutiwo untuk menambah wawasan atau pemahaman dalam menjalankan perannya sebagai pelayan Tuhan.

Keempat, untuk mencapai salah satu persyaratan akademik penyelesaian pendidikan strata satu di Sekolah Tinggi Theologia Jaffray Makassar.

3 Warren S. Benson dan Mark H. Senter, Pedoman Untuk Pelayanan Kaum Muda (Bandung: Yayasan Kalam Hidup, 1999), 154. 


\section{Metode Penelitian}

Adapun metode penelitian yang dipakai dalam penulisan skripsi ini, adalah metode kuantitatif, dengan teknik pengumpulan data, sebagai berikut :

Pertama, studi kepustakaan yaitu melalui buku-buku yang berkaitan dengan masalah pelayanan badan pengurus Jemaat dalam meningkatkan pertumbuhan kerohanian pemuda.

Kedua, dengan menggunakan metode kuisioner (angket) ${ }^{4}$ tertutup kepada pemuda jemaat untuk mengetahui sejauh mana peran badan pengurus jemaat dalam meningkatkan pertumbuhan kerohanian pemuda.

Ketiga, wawancara kepada badan pengurus Jemaat untuk mengetahui peran badan pengurus jemaat dan menguatkan data angket, serta untuk mengenal lokasi penelitian.

\section{Batasan Penelitian}

Dalam penulisan skripsi ini penulis hanya membahas mengenai bagaimana peran badan pengurus jemaat dalam meningkatkan pertumbuhan kerohaniaan pemuda Gereja Kristen Sulawesi Barat di Desa Salutiwo Mamuju.

\section{Kepustakaan}

Bambarehi, Rosyanthi F., Ivone Bonyadone Palar. "Formasi Rohani Seorang Pelayan Anak Dalam Menunjang Efektivitas Pelayanan.” Jurnal Jaffray 9, no. 2 (2011). http://dx.doi.org/10.25278/ji71.v9i2.94

Benson, Warren S. dan Mark H. Senter, Pedoman Untuk Pelayanan Kaum Muda. Bandung: Yayasan Kalam Hidup, 1999.

Mika, Petronella Tuhumury. "Implementasi Strategi Pembinaan Menuju Pertumbuhan Rohani Pemuda GKII Jemaat Sidu'ung Muara Berau." Jurnal Jaffray 11, no. 2 (2013). http://dx.doi.org/10.25278/jj71.v11i2.84

Shelton, Charles M. Moralitas Kaum Muda. Yogyakarta: Kanisius, 1990.

Wijaya, Hengki (ed.). Metodologi Penelitian Pendidikan Teologi. Makassar: Sekolah Tinggi Theologia Jaffray, 2016.

${ }^{4}$ Hengki Wijaya (ed.), Metodologi Penelitian Pendidikan Teologi (Makassar: Sekolah Tinggi Theologia Jaffray, 2016), 26. 